\title{
Decompression of multiple tension pneumatoceles in a child using computed tomography-guided percutaneous catheter placement
}

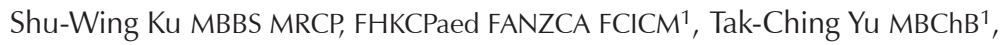 \\ Kam-Wai Chan MBBS FRCR FHKCR FHKAM(Radiol) ${ }^{2}$
}

\begin{abstract}
S-W Ku, T-C Yu, K-W Chan. Decompression of multiple tension pneumatoceles in a child using computed tomography-guided percutaneous catheter placement. Can Respir J 2011;18(6):e82e85.

Pneumatoceles can develop as a complication of pneumonia. Air accumulation inside pneumatoceles can produce a pressure effect on surrounding structures. A 15-month-old girl who developed multiple tension pneumatoceles secondary to infection caused by pneumococcus is reported. The patient experienced severe cardiorespiratory compromise that was unresponsive to conservative treatment with high-frequency oscillatory ventilation. The condition was successfully treated with computed tomography-guided percutaneous catheter placement using a pigtail catheter for decompression. A stepwise approach was adopted for removal of the catheter.
\end{abstract}

\begin{abstract}
La décompression de multiples foyers de pneumatocèle au moyen d'un cathéter percutané inséré sous contrôle tomodensitométrique

La pneumatocèle peut être une complication de la pneumonie. L'accumulation d'air dans la pneumatocèle peut produire un effet de pression sur les structures avoisinantes. Les auteurs rendent compte du cas d'une fillette de 15 mois qui a présenté de multiples foyers de pneumatocèle secondaires à une infection attribuable à un pneumocoque. La patiente a subi une atteinte cardiorespiratoire grave qui ne répondait pas à un traitement classique par ventilation oscillatoire à haute fréquence. Les pneumatocèles ont été décomprimées avec succès au moyen d'un cathéter percutané en queue de cochon, inséré sous contrôle tomodensitométrique. Une démarche progressive a été privilégiée après le retrait du cathéter.
\end{abstract}

Key Words: CT-guided catheter placement; Percutaneous catheter; Tension pneumatocele

\begin{abstract}
Dneumatocele formation is a known complication of pneumococcal pneumonia. Most pneumatoceles resolve spontaneously. We describe a pediatric case of severe pneumonia complicated by multiple pneumatoceles. Initially, conservative management with high-frequency oscillatory ventilation (HFOV) was attempted. The pneumatoceles progressively enlarged, causing a tension effect with cardiorespiratory compromise. The condition was successfully treated with percutaneous decompression using computed tomography (CT)-guided pigtail catheter placement.
\end{abstract}

\section{CASE PRESENTATION}

A previously healthy 15-month-old girl was referred from another hospital because of severe pneumonia. Her respiratory rate (RR) was 51 breaths/min on admission, with suprasternal and subcostal insucking. Chest examination showed bilaterally decreased air movement with diffuse crepitations. Chest $\mathrm{x}$-ray on admission showed bilateral diffuse patchy consolidation (Figure 1). Initial venous blood work revealed a $\mathrm{pH}$ of 7.014 , a $\mathrm{PCO}_{2}$ of $10.5 \mathrm{kPa}$, an $\mathrm{HCO}_{3}^{-}$concentration of $19.6 \mathrm{mmol} / \mathrm{L}$ and a base excess of $-13.0 \mathrm{mmol} / \mathrm{L}$. There was persistent oxygen desaturation despite being on noninvasive ventilation using bilevel positive airway pressure with the settings of inspiratory positive airway pressure $20 \mathrm{cmH}_{2} \mathrm{O}$, expiratory positive airway pressure $8 \mathrm{cmH}_{2} \mathrm{O}$, RR 40/min and fraction inspired oxygen $\left(\mathrm{FiO}_{2}\right) 100 \%$ (BiPAP Vision, Respironics, USA). She was intubated and put on pressure control ventilation (Servo-i, Maquet, Sweden) with initial settings of peak inspiratory pressure $28 \mathrm{cmH}_{2} \mathrm{O}$, positive end-expiratory pressure (PEEP) $10 \mathrm{cmH}_{2} \mathrm{O}$, RR 45/min and $\mathrm{FiO}_{2}$ 100\%. Oxygen saturation remained unstable, with difficulty in ventilation requiring repeated adjustment of ventilator settings. The highest $\mathrm{PCO}_{2}$ was $11.53 \mathrm{kPa}$. Prone ventilation was commenced on day 2 with no improvement. HFOV (SensorMedics 3100A, Viasys, USA) was applied

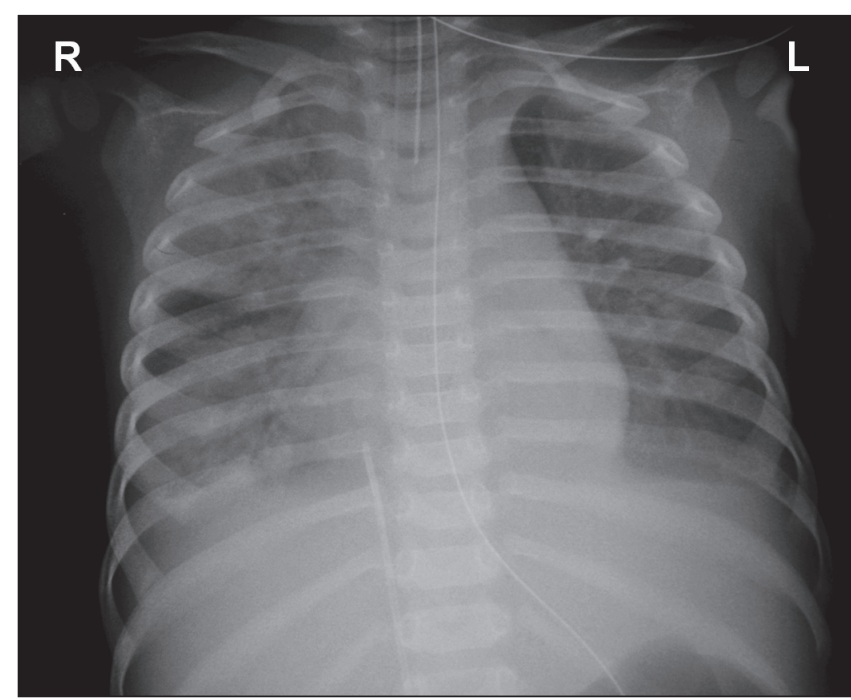

Figure 1) Chest radiograph on day 1 showing diffuse patchy consolidation

on the same day. The initial settings required for stabilization were as follows: mean airway pressure $30 \mathrm{cmH}_{2} \mathrm{O}$, amplitude $(\Delta \mathrm{P}) 40 \mathrm{cmH}_{2} \mathrm{O}$ frequency $6 \mathrm{~Hz}$, inspiratory time $33 \%, \mathrm{FiO}_{2} 100 \%$. The patient developed hypotension requiring a short duration of inotropic support. She also developed disseminated intravascular coagulation, pancytopenia and gastrointestinal bleeding requiring blood product replacement. Empirical antibiotics including cefotaxime, vancomycin and clarithromycin were commenced. Sputum culture and blood culture

${ }^{1}$ Department of Paediatrics and Adolescent Medicine; ${ }^{2}$ Department of Radiology, Pamela Youde Nethersole Eastern Hospital, Chai Wan,

Hong Kong

Correspondence: Dr Shu-Wing Ku, Department of Paediatrics and Adolescent Medicine, Pamela Youde Nethersole Eastern Hospital, 3 Lok Man

Road, Chai Wan, Hong Kong. Telephone 852-25956860, fax 852-29045371, e-mail alku1298@hkstar.com 


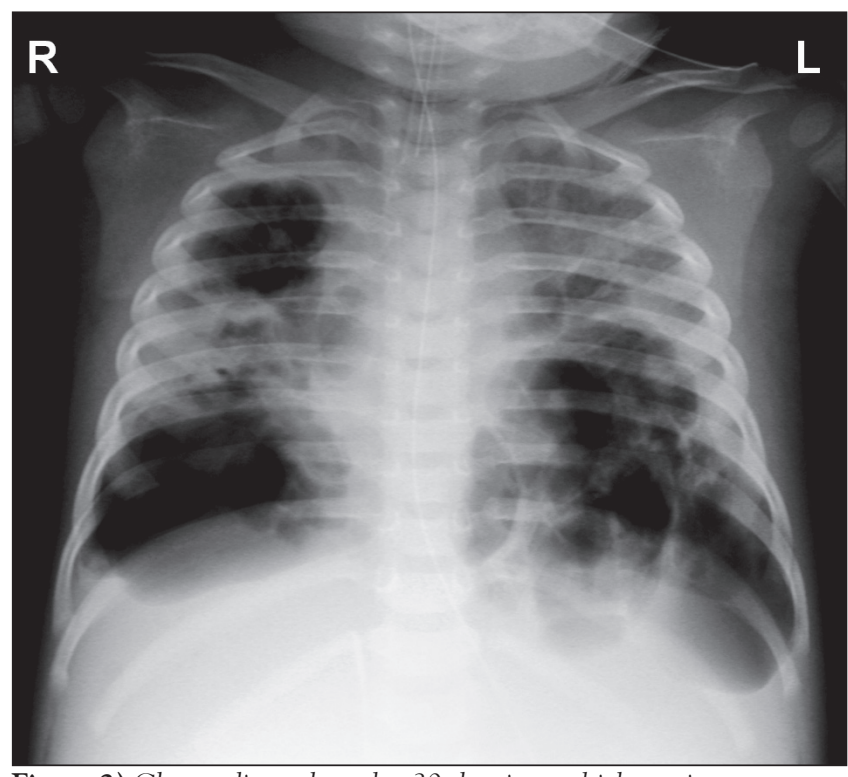

Figure 2) Chest radiograph on day 30 showing multiple tension pneumatoceles with diffuse involvement and mediastinal shift

showed Streptococcus pneumoniae that was sensitive to penicillin $G$ and cefotaxime. She was subsequently continued on cefotaxime. Respiratory syncytial virus (RSV) was isolated from the nasopharyngeal aspirate.

The patient's condition improved and she was returned to supine positioning on day 3 . She was able to wean down the HFOV settings. She deteriorated again on day 5 due to nosocomial pneumonia. Antibiotics were empirically switched to penicillin $G$ and ceftazidime on day 5 to cover both pneumococcus and nosocomial organisms. Repeated sepsis workup showed no more evidence of pneumococcus, but sputum culture revealed Acinetobacter species. She was put on meropenem, vancomycin and amikacin starting on day 8 .

Pneumatoceles first appeared on chest $\mathrm{x}$-ray on day 10, and she developed bilateral tension pneumothoraces on day 11. Bilateral chest tube placement was performed. Air re-accumulation developed a few days later in both sides, requiring placement of a new chest tube. Serial chest $\mathrm{x}$-rays revealed development of bilateral multiple pneumatoceles with gradual increases in the size and extent of involvement. However, there was no further re-accumulation of pneumothoraces. Repeated sputum cultures revealed no bacterial growth. Amikacin was continued up to day 17 , and vancomycin was discontinued on day 21 . She remained on meropenem after stopping amikacin and vancomycin given her intermittent fever with persistent high $\mathrm{C}$-reactive protein levels. Because there were no additional pneumothoraces, all chest drains were removed by day 23 .

Despite resolution of pneumothoraces, difficulty in mechanical ventilation remained. A chest $\mathrm{x}$-ray showed a progressive increase in the size of the pneumatoceles, with mediastinal shift toward the right side (Figure 2). Echocardiography on day 30 revealed compressed left ventricles with normal contractility. The $\Delta \mathrm{P}$ was increased to $70 \mathrm{cmH}_{2} \mathrm{O}$ using lowest frequency at $4 \mathrm{~Hz}$. The $\mathrm{FiO}_{2}$ was $100 \%$. In view of the progressive deterioration while on conservative management, an interventional approach with percutaneous catheter decompression was decided.

Placement of a CT-guided pigtail catheter was arranged on day 31 . The ventilator mode was switched to pressure-regulated volume control (Servo-i, Maquet, Sweden), which was afforded by the portability of the ventilator in the radiology suite. A CT scan of the thorax revealed numerous cystic lesions in both lungs, with communication to the bronchial tree. The largest cystic lesion was as large as $86.4 \mathrm{~mm}$ $\times 45 \mathrm{~mm} \times 48.6 \mathrm{~mm}$ at the anterior aspect of the right lower lobe. The residual aerated lung was the right middle lobe and subsegmental portion of the anterior segment of the right upper lobe. The right lower
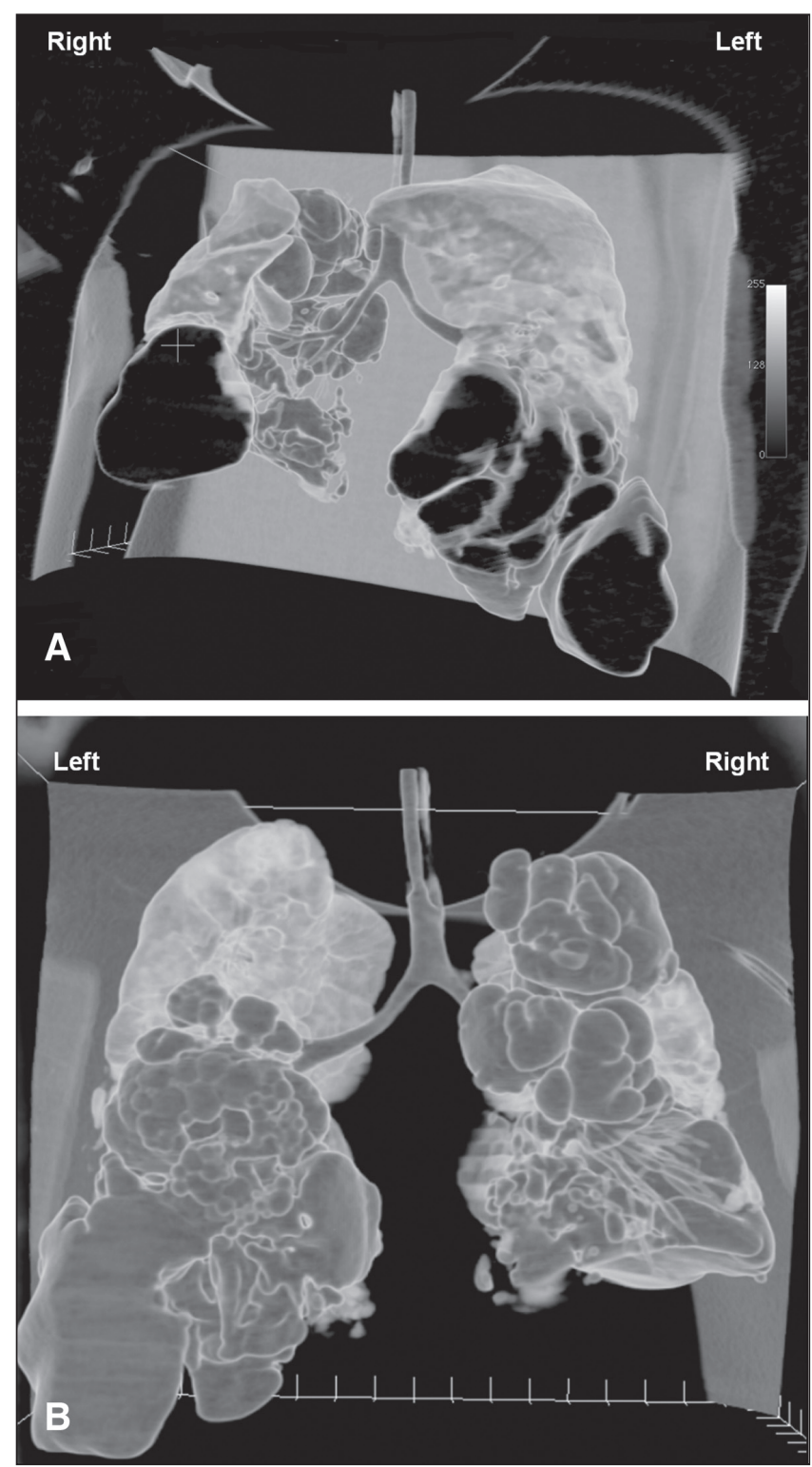

Figure 3) Three-dimensional reconstructed computed anterior (A) and posterior (B) tomography images showing diffuse destruction of lung tissues with multiple cystic lesions. The residual aerated parts were the right middle lobe, subsegmental portion of anterior segment of right upper lobe and the left upper lobe

lobe was replaced by multiple cystic lesions. A tiny loculated pneumothorax was apparent in the right lung. The largest cystic lesion in the left side was as large as $49.1 \mathrm{~mm} \times 33.3 \mathrm{~mm} \times 50.1 \mathrm{~mm}$ at the lateral aspect of the left lower lobe and displayed bulging lateral borders. The residual aerated lung was the left upper lobe. The left lower lobe was replaced by multiple cystic lesions (Figure 3). A 6 Fr pigtail catheter was inserted anteriorly into the largest pneumatocele in the right lower lobe, resulting in effective air drainage. The catheter was connected to a chest drainage system with a suction pressure of $10 \mathrm{cmH}_{2} \mathrm{O}$.

The patient was maintained on pressure-regulated volume control after catheter placement. There was significant leaking of air. The ventilator settings on day 32 were as follows: TV inspiratory $84 \mathrm{~mL}$, TV expiratory $62 \mathrm{~mL}$, minute volume inspiratory $3.4 \mathrm{~L} / \mathrm{min}$, minute volume expiratory $2.4 \mathrm{~L} / \mathrm{min}, \mathrm{RR} 40 / \mathrm{min}, \mathrm{FiO}_{2} 65 \%$, PEEP $6 \mathrm{cmH}_{2} \mathrm{O}$ and inspiratory time ( $\mathrm{Ti}) 0.62 \mathrm{~s}$. Arterial blood gas under these settings revealed $\mathrm{pH} 7.4, \mathrm{PCO}_{2} 7.3 \mathrm{kPa}$ and $\mathrm{PO}_{2} 12.73 \mathrm{kPa}$. Her fever was intermittent while she remained on meropenem. A sepsis workup revealed 


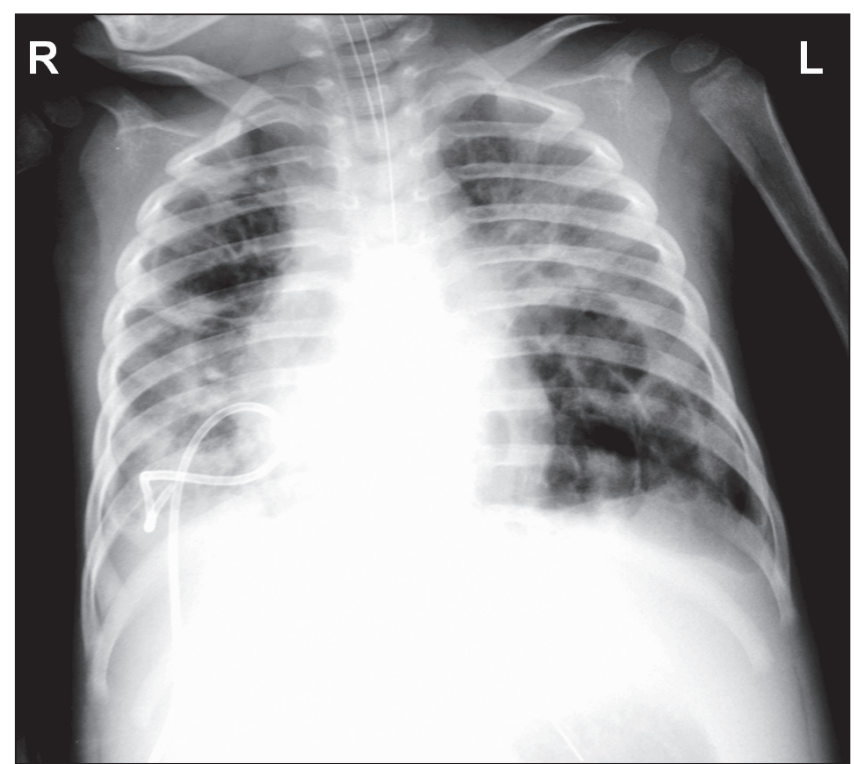

Figure 4) Chest radiograph on day 39 showing collapse of the right lower lobe pneumatocele after catheter drainage and decrease in the size of other pneumatoceles

the presence of Candida parapsilosis from sputum and the tip of the arterial line catheter. Meropenem was discontinued on day 32, and a course of intravenous fluconazole was completed.

No air leak was observed from the catheter on day 35. A chest $\mathrm{x}$-ray also showed a significant decrease in the size of the right lower lobe pneumatocele. The size of the other pneumatoceles also decreased (Figure 4). Catheter placement into the large left lower lobe pneumatocele was not performed because of the improvement and the inherent risks in performing an invasive procedure. As her pneumatoceles decreased in size, the ventilator parameters also improved. There was a decrease in leaking, with TV inspiratory $75 \mathrm{~mL}$ and TV expiratory $69 \mathrm{~mL}$. $\mathrm{FiO}_{2}$ was weaned down to $40 \%$. A decision was made to remove the pigtail catheter. Due to the risk of re-accumulation of air after removal of the catheter, it was decided to remove the catheter using a stepwise approach. The catheter was shifted outward by $1 \mathrm{~cm}$ to $2 \mathrm{~cm}$ every one to two days. The progress was monitored by chest $\mathrm{x}$-ray and observation of any air leakage within the drainage system. There was no recurrence of air collection, and the catheter was removed on day 44 .

The ventilator mode was switched to automode with a combination of pressure control and pressure support on day 42. The settings on removal of the catheter were: PEEP $4 \mathrm{cmH}_{2} \mathrm{O}$, pressure above PEEP $8 \mathrm{cmH}_{2} \mathrm{O}$ (PC and $\mathrm{PS}$ ), $\mathrm{FiO}_{2} 30 \%$, rate $40 / \mathrm{min}$, Ti $0.6 \mathrm{~s}$, inspiratory cycle off $30 \%$ and trigger timeout $5 \mathrm{~s}$. The weaning process was continued in the automode. Tracheostomy was performed on day 49 given the prolonged mechanical ventilation. The patient developed drug withdrawal syndrome on weaning from sedation. By day 80 , she could be completely weaned off all sedative drugs including midazolam, fentanyl and chloral hydrate. She could be weaned off the ventilator completely on day 90. She was decannulated on day 106 and weaned to room air on day 116 . She was finally discharged on day 140 . A chest $\mathrm{x}$-ray before discharge showed a significant decrease in the extent of involvement of the pneumatoceles (Figure 5). Investigation after discharge from hospital showed normal immunoglobulin $\mathrm{E}$ and alpha 1-antitrypsin levels. A thoracic CT scan five months later showed substantial interval decrease in the size and number of previous gasfilled cavities. There was no neurological deficit.

\section{DISCUSSION}

Pulmonary pneumatoceles are thin-walled, air-filled spaces that develop within the lung parenchyma. They can develop after injury or inflammation. Most pneumatoceles are caused by Staphylococcus

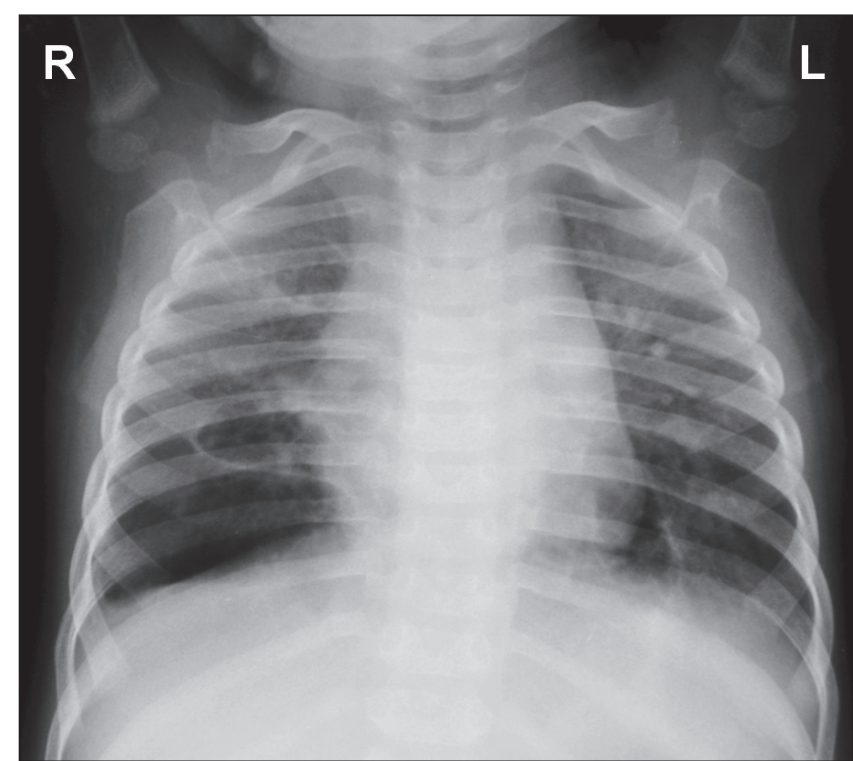

Figure 5) Chest radiograph on day 130 showing significant decrease in the number and size of the pneumatoceles

aureus; other pathogens that may be associated include Streptococcus pneumoniae, Haemophilus influenzae and Klebsiella pneumoniae (1). Wexler et al (2) reported that in their series of 111 patients with pneumococcal pneumonia, 39\% experienced pulmonary complications, with pneumatocele development in 19\% (2). Pneumatoceles are also reported in association with infection caused by RSV $(3,4)$ and in Acinetobacter pneumonia (5). Pneumatoceles can also develop secondary to positive pressure ventilation, especially in premature infants (6). In our patient, pneumococcal infection was the most likely etiology of the pneumatoceles. However, the probable role of RSV infection, Acinetobacter infection and mechanical ventilation as additional predisposing factors, whether alone or in combination, cannot be completely excluded.

The exact mechanism of pneumatocele formation is unknown. One proposed mechanism is a check-valve mechanism postulated by Quigley and Fraser (7). In their hypothesis, tissue destruction in necrotizing pneumonia can lead to cavity formation. Subsequently, irritation and inflammation of a draining bronchiole can lead to the formation of a mucous flap that is focally adherent to the airway wall. The mobile intracavitary portion can alternately open and close the bronchiolar orifice, acting as a check-valve (7). Air can accumulate and produce a tension effect.

The majority of pneumatoceles resolve spontaneously $(1,8)$, with $85 \%$ spontaneous involution reported in one series (8). Development of multiple tension pneumatoceles in pediatric patients is rare. Tension pneumatoceles can rupture and cause pneumothorax or bronchopleural fistula $(9,10)$. Endotracheal intubation of patients with tension pneumatoceles is a high-risk procedure because patients can progress to cardiac arrest on intubation (11).

Previously described management approaches to pneumatoceles include selective bronchial intubation, unilateral balloon occlusion of the affected bronchus and lobectomy $(3,12,13)$. These approaches were not applicable in our patient because of the bilateral diffuse involvement. One case describing the successful management of tension pneumatocele with HFOV alone has been reported (14). Conservative management with HFOV was initially attempted in our patient, but the pneumatoceles progressively enlarged, resulting in an increasing tension effect that caused compression of the left ventricle, which was evident during echocardiography. There was also increasing difficulty in maintaining satisfactory ventilation. Therefore, an interventional approach via catheter drainage was decided. A surgical approach was not adopted because the patient's unstable clinical 
TABLE 1

Summary of reports of catheter drainage of tension pneumatocele(s)

\begin{tabular}{|c|c|c|c|c|c|c|}
\hline Author (reference), year & Number & Age & Etiology & Catheter & Method & Outcome \\
\hline Zudhi et al (9), 1996 & 4 in 2 patients & 2 to 3 years & $\begin{array}{l}\text { Chickenpox, Pneumococcus, } \\
\text { Group A streptococcus }\end{array}$ & $\begin{array}{l}8.5 \mathrm{Fr} \\
\text { pericardial }\end{array}$ & $\begin{array}{l}\text { Computed } \\
\text { tomography }\end{array}$ & Resolved \\
\hline Kogutt et al (15), 1999 & Bilateral, multiple & 1 month & Staphylococcus aureus & 5 Fr pigtail & Fluoroscopy & $\begin{array}{l}\text { Recurred, followed by } \\
\text { thoracotomy }\end{array}$ \\
\hline Arias-Camison et al (12), 2001 & Bilateral, multiple & Neonate & PIE & $\begin{array}{l}\text { 5.5 Fr pigtail } \\
\times 2\end{array}$ & Fluoroscopy & Resolved \\
\hline Fujii and Moulton (3), 2003 & 1 & Neonate & PIE + RSV & 6 Fr pigtail & Fluoroscopy & Resolved \\
\hline Fujii and Moulton (4), 2008 & 1 & Neonate & PIE + RSV & 5 Fr pigtail & VATS & Resolved \\
\hline Present case & Bilateral, multiple & 15 months & Pneumococcus & 6 Fr pigtail & $\mathrm{CT}$ & Resolved \\
\hline
\end{tabular}

CT Computed tomography; PIE Pulmonary interstitial emphysema; RSV Respiratory syncytial virus; VATS Video-assisted thoracic surgery

condition made thoracotomy a high-risk procedure. There are only a few case reports in the literature detailing catheter drainage of a tension pneumatocele in pediatric patients $(3,4,9,12,15)$, only one of which described successful treatment in a neonate with bilateral diffuse involvement who responded to catheter drainage alone (12) (Table 1). Although blind multiple percutaneous needle decompressions using venous catheters have been reported to be successful in emergent situations (16), we prefer catheter drainage under radiological guidance to minimize the risk of developing complications.

Our patient experienced rapid clinical and radiological improvement after catheter insertion. No air leaks were observed three days after the procedure. Therefore, we decided to remove the catheter $24 \mathrm{~h}$ after cessation of air drainage. There is no information in the literature about the optimal method of catheter removal. However, there is a report of re-accumulation of air over an $18 \mathrm{~h}$ period after catheter removal despite no recurrence of air collection when the catheter was clamped for $24 \mathrm{~h}$ before removal (15). We decided to remove the pigtail catheter in a stepwise approach by shifting the catheter a short distance $(1 \mathrm{~cm}$ to $2 \mathrm{~cm}$ ) every one to two days while monitoring chest $\mathrm{x}$-rays and the reappearance of air leaks in the chest drain. We believed that by keeping the catheter opening inside the air space and slowly removing it - instead of removing it with one single action - we might be able to detect late re-accumulation of air after the usual recommended time of catheter removal. The removal process was monitored by observation of the chest drainage output and

\section{REFERENCES}

1. Ïmamoglu M, Çay A, Kosucu P, et al. Pneumatoceles in postpneumonic empyema: An algorithmic approach. J Pediatr Surg 2005;40:1111-7

2. Wexler ID, Knoll S, Picard E, et al. Clinical characteristics and outcome of complicated pneumococcal pneumonia in a pediatric population. Pediatr Pulmonol 2006;41:726-34.

3. Fujii AM, Moulton S. Percutaneous catheter evacuation of a pneumatocele in an extremely premature infant with respiratory failure. J Perinatol 2003;23:516-8.

4. Fujii AM, Moulton S. VATS management of an enlarging multicystic pneumatocele. J Perinatol 2008;28:445-7.

5. Hunt JP, Buechter KJ, Fakhry SM. Acinetobacter calcoaceticus pneumonia and the formation of pneumatoceles. J Trauma 2000;48:964-70.

6. Hussain N, Noce T, Sharma P, et al. Pneumatoceles in preterm infants-incidence and outcome in the post-surfactant era. J Perinatol 2010;30:330-6.

7. Quigley MJ, Fraser RS. Pulmonary pneumatocele: Pathology and pathogenesis. Am J Roentgenol 1988;150:1275-7.

8. Kunyoshi V, Cataneo DC, Cataneo AJM. Complicated pneumonias with empyema and/or pneumatocele in children. Pediatr Surg Int 2006;22:186-90.

9. Zuhdi MK, Spear RM, Worthen HM, Peterson BM. Percutaneous catheter drainage of tension pneumatocele, chest $\mathrm{x}$-ray to detect air re-accumulation. In case of recurrence of air leakage, the need to insert a new catheter might be reduced because of the in-situ catheter already in place, given the inherent risks of chest drain insertion. The catheter removal process could be suspended and resumed after cessation of air drainage. Another reason is that shifting of the catheter might enhance drainage of different air compartments because of the change in the position of catheter openings. No complications such as bronchopleural fistula or pneumothorax occurred after catheter removal.

Our patient gradually recovered after the procedure. Although the majority of pneumatoceles resolve spontaneously $(1,8)$, the pressure effect with continuous deterioration justified an interventional approach. As the patient became more stable after the pressure effect was relieved, time should be allowed for natural resolution to occur. If pneumatoceles fail to resolve, underlying genetic or immunological disorders should be considered. One example is hyperimmunoglobulin E syndrome (11). Therefore immunoglobulin E and alpha 1-antitrypsin levels were checked in our patient. The results were normal.

\section{CONCLUSION}

Our experience from the present case suggests that percutaneous catheter drainage under CT-guidance is an effective option for multiple tension pneumatoceles with diffuse lung involvement. A stepwise approach for catheter removal may be considered.

secondarily infected pneumatocele, and lung abscess in children. Crit Care Med 1996;24:330-3.

10. Amitai I, Mogle P, Godfrey S, Aviad I. Pneumatocele in infants and children. Report of 12 cases. Clin Pediatr 1983;22:420-2.

11. Al-Saleh S, Grasemann H, Cox P. Necrotizing pneumonia complicated by early and late pneumatoceles. Can Respir J 2008;15:129-32

12. Arias-Camison JM, Kurtis PS, Feld RS, Morrison P, Bourque MD, DeSilva HN. Decompression of multiple pneumatoceles in a premature infant by percutaneous catheter placement. J Perinatol 2001;21:553-5.

13. Andreou A, Papouli M, Netskos D, Papadopoulou F, Rossiou E. One-sided high-frequency oscillatory ventilation in the management of an acquired neonatal lobar emphysema: A case report and review. J Perinatol 2001;21:61-4.

14. Shen HN, Lu FL, Wu HD, Yu CJ, Yang PC. Management of tension pneumatocele with high-frequency oscillatory ventilation. Chest 2002:121:284-6.

15. Kogutt MS. Lutrell CA. Puyau FA, Tieman EK. Decompression of pneumatocele in a neonate by percutaneous catheter placement. Pediatr Radiol 1999;29:488-9.

16. Wu ET, Chen JS. Management of multiple tension pneumatoceles refractory to tube thoracostomy decompression. Ann Thorac Surg $2006 ; 81: 1482-4$. 


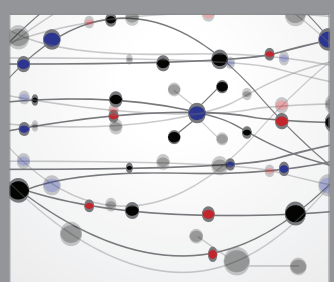

The Scientific World Journal
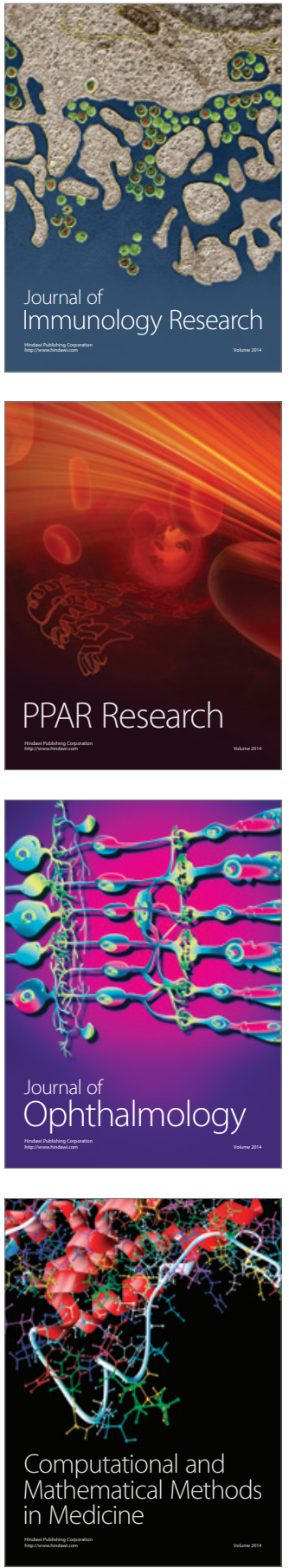

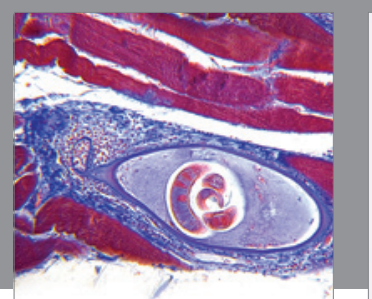

Gastroenterology Research and Practice

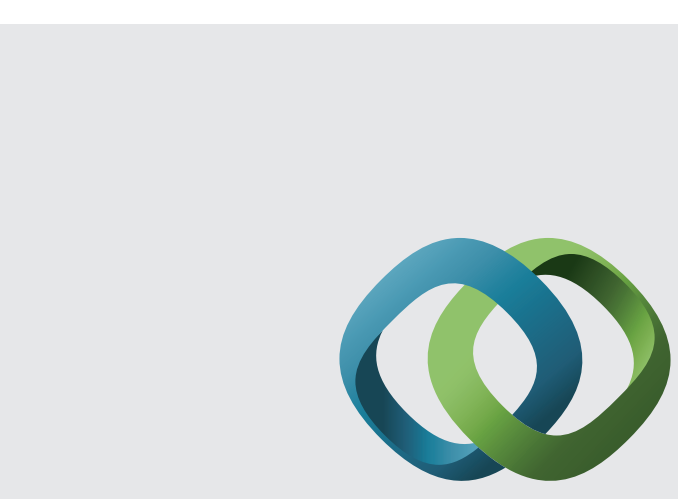

\section{Hindawi}

Submit your manuscripts at

http://www.hindawi.com
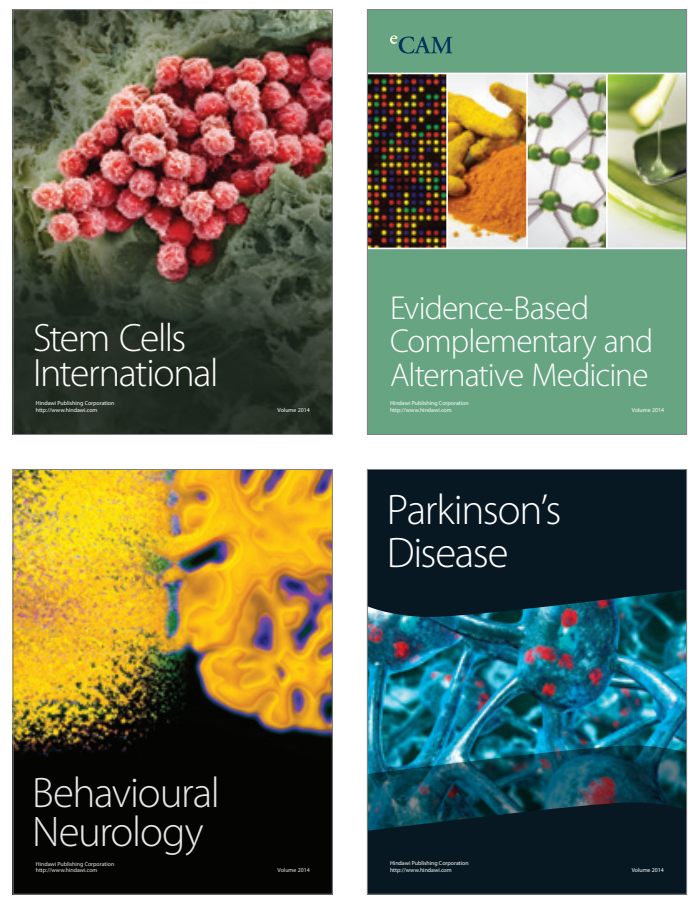
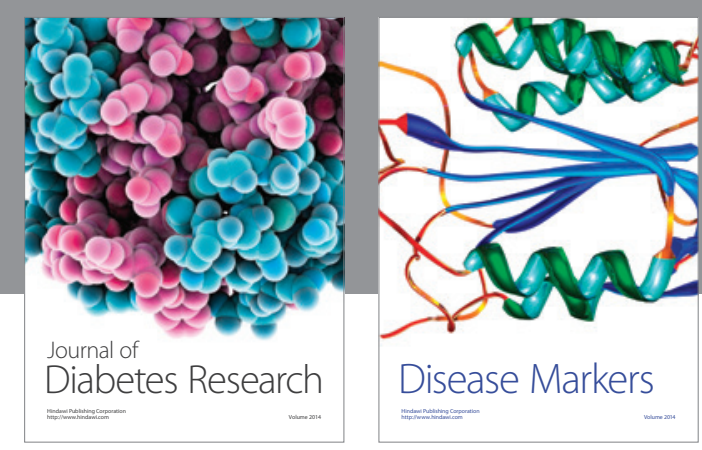

Disease Markers
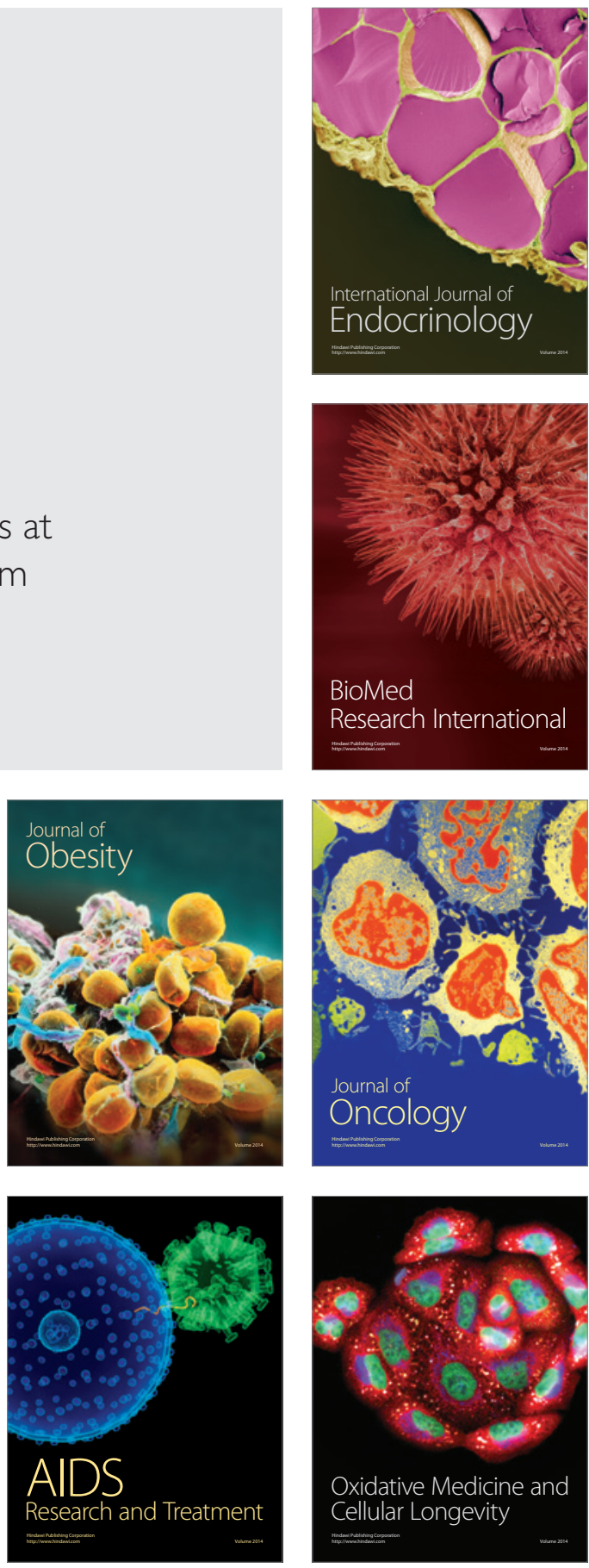